\title{
03 | Lo verde como sistema: espacios verdes y vida al aire libre en la Holanda de entreguerras a través de las páginas de la publicación neerlandesa de 8 en Opbouw. Green as a Urban System: green areas and outdoor life habits in the interwar period as seen from the dutch magazine de 8 en Opbouw_Isabel de Cárdenas Maestre
}

El interés por los espacios verdes y la vida al aire libre resurgió a principios del siglo pasado en Centroeuropa, vinculado a los movimientos por la reforma de la vida o Lebensreform. [1] Holanda -junto a Alemania- fue uno de los países en los que más se manifestó esta tendencia, materializándose en proyectos de altísimo interés, que indican un camino que los arquitectos holandeses -con excepción del periodo bélico- nunca llegaron a abandonar. Los ejemplos que se muestran en estas páginas reflejan la urgencia con la que se denunció la falta de espacios en los que disfrutar del aire libre y las soluciones que estos arquitectos ${ }^{1}$ plantearon. Estas propuestas quedaron reflejadas en las páginas de la revista neerlandesa de 8 en Opbouw durante los años de entreguerras. El conjunto es un capítulo ineludible de la historia del paisajismo y de la planificación urbana con ejemplos tan singulares como el Plan Verde para Rotterdam o el Boschpark de Ámsterdam.

Todas estas aportaciones conformaron una nueva visión que permaneció oculta durante muchos años pero que resurgió con el renacer de los movimientos ecologistas a finales de los años 60 y que hoy es irrenunciable. Conocer estos orígenes es, por tanto, obligado.

\section{La publicación holandesa de 8 en Opbow ${ }^{2}$}

de 8 en Opbouw fue una publicación vinculada al funcionalismo y la Niewe Bauen que siguió muy de cerca el desarrollo de la Arquitectura Moderna durante los treinta. Es, por tanto, una experiencia única por su constancia y longevidad, y por haber seguido tan de cerca los avatares de la vanguardia internacional. Sus 12 años de existencia hacen de esta publicación un documento único que, no solo muestra las experiencias holandesas, sino que incorpora aportaciones de Alemania, Francia, Rusia o Estados Unidos. La revista permite seguir el desarrollo de la Arquitectura Moderna desde el año 1932, en que se fundó, hasta su extinción por motivos políticos en $1943^{3}$

Editada por arquitectos de ideas vinculadas al funcionalismo y la Neue Sachlichkeit, de 8 en Opbouw es heredera de publicaciones anteriores como 110 internationale, desaparecida en 1929. Si $i 10$ mostraba un panorama artístico más general, incorporando experiencias desde todas las artes, los arquitectos que fundaron de 8 en Opbouw optaron por una visión más centrada en la arquitectura y su papel esencial en el proceso del cambio social a través de la vivienda y el

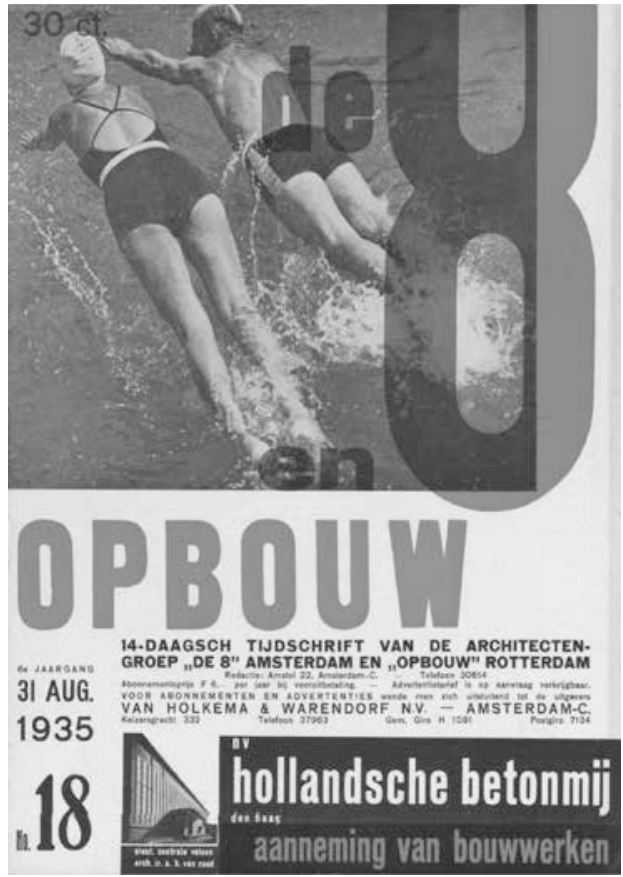

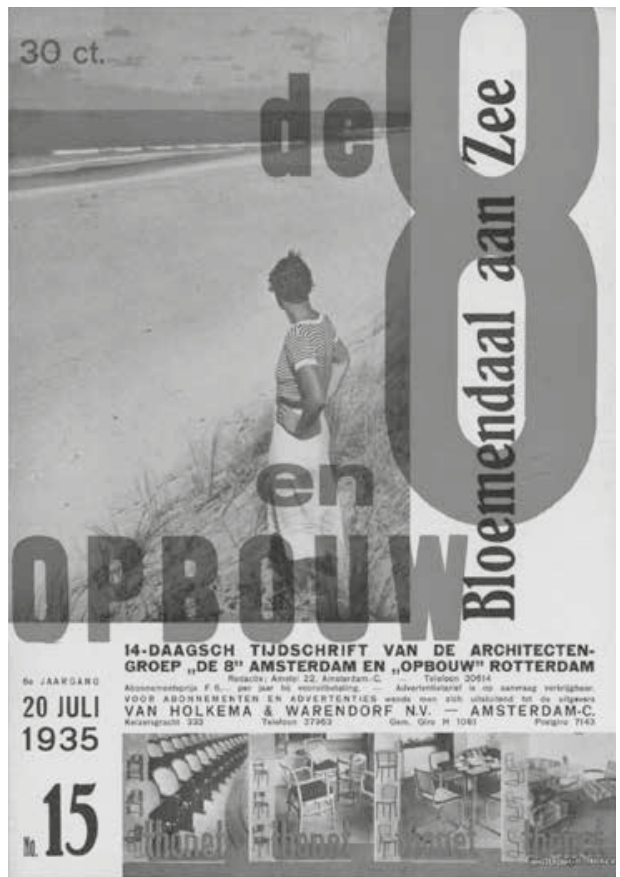

Resumen pág 56 | Bibliografía pág 63

Universidad Politécnica de Madrid. Isabel de Cárdenas Maestre es Arquitecto y Doctora por la UPM. Profesora Asociada en la Universidad Politécnica, impartiendo la asignatura de "Paisaje y Jardín" en el DCA de la ETSAM. Su campo de investigación pertenece a la teoría de la Arquitectura y el Paisaje. Dirige varias tesis doctorales en el área de la Composición. Ha sido Directora del Grado en Paisajismo por la UCJC.

i.cardenas@upm.es

Palabras clave

Neues Bauen, Lebensreform, paisaje, parque, de 8 en Opbouw, Rotterdam, Groenplan, higiene, urbanismo

\section{Keywords}

Neues Bauen, Lebensreform, landscape, park, de 8 en Opbouw, Rotterdam Groenplan, hygiene, urban planning

Método de financiación

Financiación propia

DOI

10.24192/2386-7027(2020)(v14)(03)

[1] Portada de la revista de 8 en Opbouw del 31 de agosto de 1935. Fuente: de 8 en Opbouw, n' 18, 1935.

[2] De 8 en Opbouw. Portada de julio de 1935: complejo de baños Bloemendaal aan Zee, de Arthur STAAL. Fuente: de 8 en Opbouw, n 15, 1935.

[3] Fotografías mostrando los baños de sol y las virtudes de la vida al aire libre. Fuente: FALKENBERG, Ida, "Her Naturbad", de 8 en Opbouw, n ${ }^{\circ} 17$ agosto 1933 , p. 151. 
planeamiento urbano. El chocante nombre proviene de la unión de dos grupos de arquitectos que se fusionaron: de 8 (el 8), de Ámsterdam, junto con Group 32 y los OPBOW (Construcción) de Rotterdam. Merkelbach, Duiker o Wiebenga, por ejemplo, provenían de de 8, mientras que Mart Stam, Van der Vlugt, Oud, Rietveld o Cor van Eesteren formaban parte del grupo de Rotterdam. Muchos de ellos habían participado en los CIAM y tenían contactos internacionales. Algunos de ellos, como Stam, Oud o Rietveld ya habían obtenido reconocimiento por parte de profesionales de otros países por una carrera relevante dentro de la nueva arquitectura.

\section{Los movimientos para la reforma de la vida}

Los movimientos Lebensreform surgieron en diferentes países durante el siglo XIX, especialmente Alemania, Rusia y Estados Unidos. En Alemania, estas teorías se desarrollaron durante el periodo "guillermino", que provenía de un pensamiento utópico evolucionado hacia un fomento de la vida natural. A partir de los principios románticos "roussonianos", y alimentado por un contexto de crítica a la ciudad decimonónica, el cambio afectaría al modo de vida occidental y se manifestaría en muy diferentes aspectos de la cotidianidad. Esta revolución fue especialmente patente en la influencia que tuvo la incorporación de la naturaleza sobre la reformulación de las teorías urbanas, tema absolutamente central entre los últimos años del siglo XIX y la tercera década del siglo XX. Una de las grandes novedades -con muchos matices entre las diferentes propuestas- fue la obsesión por la eliminación de las barreras entre la ciudad y el campo, que se materializó en la incorporación de lo verde en la ciudad, sobre todo a través de los grandes parques y la incorporación de la "zona verde" dentro de los estándares de cálculo de superficie en el diseño de la ciudad.

\section{Fomento de la vida al aire libre}

Otros cambios en la forma de vida de los europeos tuvieron impacto en el diseño urbano. La actividad física del cuerpo y el contacto con la tierra -incluidas las labores agrícolas- pasó a ocupar un lugar central. [2] Las nuevas concepciones coincidían -como muchos de los movimientos juveniles en búsqueda del "hombre nuevo"- en las referencias a la educación física y a la cultura del cuerpo. Es llamativo el auge de prácticas nudistas. Uno de los motivos de la irrupción de teorías que fomentaban el mayor contacto de los cuerpos con el sol pudo ser la Gripe Española (1918-1919) que dejó en toda la Europa posbélica un número de muertos de entre 20 y 40 millones. La creencia médica en que la vitamina $D$ podría proteger frente al virus de la gripe ${ }^{4}$ pudo ser otro de los motivos que impulsaron a prescribir los baños de sol. En medio de la pandemia actual es interesante entender de qué manera afectó este drama a la estimulación por ampliar los espacios verdes y la demanda por mejorar la higiene social.

\section{El cuerpo, el deporte ${ }^{5}$ y el agua}

Las primeras referencias en de 8 en Opbouw a los baños muestran esa fe en los beneficios de los baños de agua y sol, con ejemplos extranjeros, sobre todo alemanes ${ }^{6}$. [3] Las experiencias

[3]

\footnotetext{
${ }^{1}$ Se trataba de arquitectos de primerísima linea como J. J. P. Oud, Mart Stam, Gerrit Rietveld, Johannes Duiker, Cor Van Eesteren o un jovencísimo Bakema.

2 Para más información acerca de la revista de 8 en Opbouw, consultar: BOCK, Manfred, "Ensayo sobre de 8 en Opbouw". Prologado por GARCIÁA GARCIA, Rafael, Cuaderno de Notas, $n^{\circ} 8,2000$, pp. 3-62.

${ }^{3}$ La llegada de los alemanes en 1940 no supuso el cierre de la publicación, ya que la politica de Reich no llegó a manifestarse en contra. Sería ya en 1943 cuando el gobierno alemán decidió la suspensión.

${ }^{4}$ BROWN, Jeremy. Influenza: The HundredYear Hunt to Cure the 1918 Spanish Flu Pandemic. Nueva York: Atria Paperback, 2018.

${ }^{5}$ Monográfico sobre deportes. De 8 en Opbouw, n 16, 1936.

${ }^{6}$ Monográfico sobre baños y piscinas públicos. De 8 en Opbouw, $\mathrm{n}^{\circ} 16,5$ de agosto 1932 y De 8 en Opbouw, $\mathrm{n}^{\circ} 18$, 1935
}

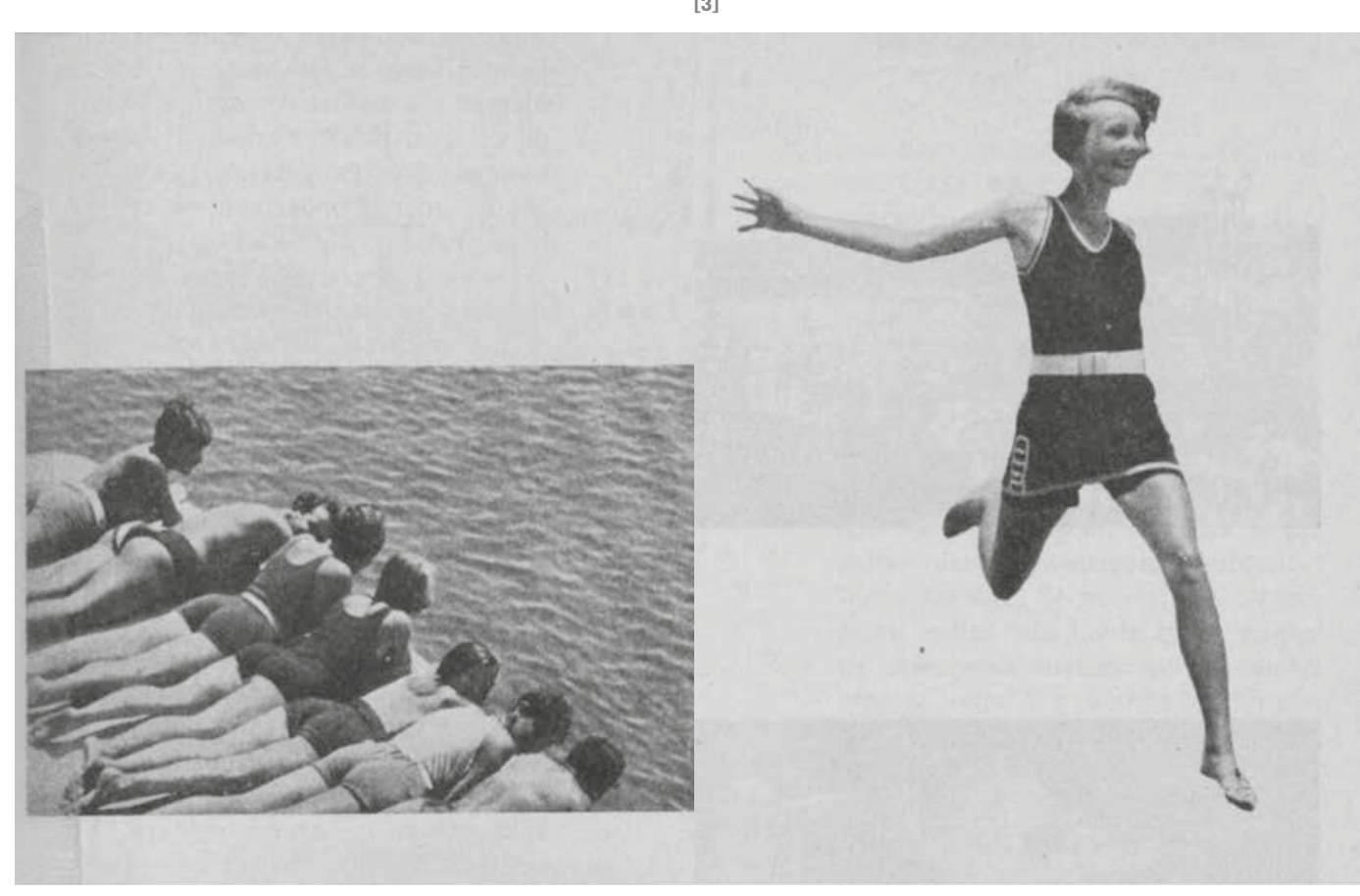




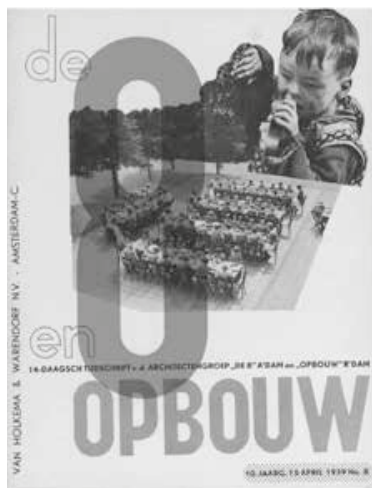

[4]

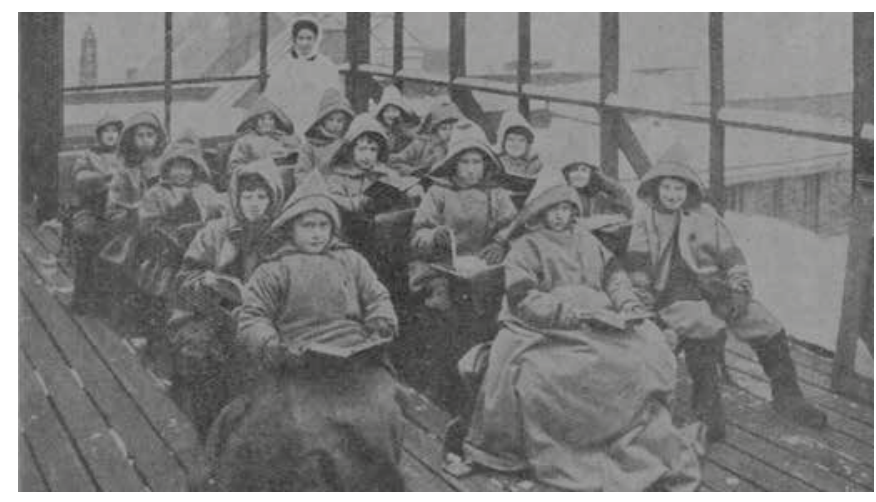

[5]

alemanas en la creación de instalaciones acuáticas de iniciativa municipal, como la del balneario en el Wannsee, de Martín Wagner, el complejo de Dresde-Briesnitz, los baños de Marienbad o el Geirg-Arnohldbad ${ }^{7}$, eran recientes.

En lagos, ríos, mar y piscinas, comenzaron a aparecer en Holanda proyectos de centros deportivos que facilitaban el baño a los ciudadanos. Algunos fueron de gran magnitud, como el de Arthur Staal en Bloemendaal aan Zee ${ }^{8}$. El lugar era idóneo como centro vacacional, por ser la zona de costa más próxima a las ciudades de Ámsterdam y Haarlem -incluye esquemas y estadísticas de acceso-. Tras un estudio exhaustivo del lugar, de la topografía y del paisaje de la zona, propuso un complejo de baños que incluía hasta un teatro al aire libre, restaurantes, casas de fin de semana y zonas deportivas. Aprovechaba la topografía del lugar para formar un lago para baño y ejercicios náuticos. De los grandes proyectos no fue el único, aunque sí el más extenso. En el número de julio de 1935 se señalaban también otros proyectos, ninguno de los cuales se llegaría a construir, que aprovechaban el terreno para la creación de lagos artificiales para el baño y el deporte.

\section{“Una escuela saludable para un niño sano" 9}

También las condiciones de vida de la infancia y su papel activo en el disfrute de la ciudad fueron objeto de atención para los urbanistas. Los nuevos sistemas revolucionarios docentes exigían un nuevo tipo arquitectónico: het niewe school. [4]

Uno de los números más interesantes acerca de las escuelas es el monográfico de abril de $1932{ }^{10}$, que recoge ejemplos de nuevas escuelas en Europa y Estados Unidos. Muchos de los principios que regían la concepción de los nuevos centros educativos están hoy en día asumidos, como la higiene y la luminosidad en las aulas, pero no quedaban ahí las exigencias de aquellos años: la audaz propuesta exigía la educación del niño al aire libre siempre que las condiciones climáticas lo permitieran -iincluso bajo $00^{\circ}$ 11 $^{11}$. [5] Uno de los ejemplos que mejor expresan estas premisas es el Friedrich-Ebert reform-school, de Ernst May en Frankfurt ${ }^{12}$ : aulas abiertas, cada una de las cuales se corresponde con un jardín. [6] [7]

Los centros necesitaban una gran cantidad de aulas exteriores, totalmente abiertas, y, en muchas ocasiones, ajardinadas. Huyendo de la típica imagen de "colegio", trataban de evitar el edificio compacto. Las nuevas construcciones se atomizaban y se dispersaban por el terreno, y a cada aula cerrada le correspondía un aula abierta.

\section{La ciudad verde: lo verde como sistema}

Hasta finales de los años treinta no se materializarían las nuevas ideas de la introducción del verde en la ciudad, pero en pocos años se convirtió en el tema principal de la regeneración urbana, y así lo demuestran las dos grandes intervenciones: el Amsterdam Boschpark (Bosque de Ámsterdam) y el Groenplan Rotterdam (Plan verde para Rotterdam). [8] A estas iniciativas vinieron asociadas otras de menor escala, pero que reflejan la necesidad de basar las intervenciones en la estructura de los espacios verdes.

Los años treinta fueron testigo de una nueva concepción de la ciudad estructurada en torno a la relación entre la ciudad construida y los espacios verdes. A la idea de defender el verde en toda la ciudad corresponde la tendencia a cualificar el paisaje urbano a través de una planificación más controlada, basada en la estética y la funcionalidad de los espacios abiertos. Las primeras referencias a la introducción del parque y los espacios verdes en la ciudad que publica la revista es un artículo en 1936 con las nuevas teorías urbanas de Le Corbusier, "La Ville Radieuse" 13, que incluye fotografías, planos y dibujos.

[4] Portada de de 8 en Opbouw del 15 de abril de 1939, uno de los muchos monográficos que dedicaron los editores de la revista a las escuelas y a las pedagogías modernas. Fuente: de 8 en Opbouw, n 8, 1939.

[5] Fotografia que muestra un grupo de niños y su profesora en un colegio, en Chicago, 1919. La reforma de la educación y los nuevos sistemas pedagógicos exigían que los niños pudieran dar clase al aire libre. Fuente: DUIKER, Jan, "Enn gezonde school voor het gezonde kind". De 8 en Opbouw, n 9, 28 de abril de 1932, p. 90
7 FALKENBERG, Ida. "Her Naturbad". De 8 en Opbouw, $n^{\circ}$ 17, 1933, pp. 150-153.

8 STAAL, Arthur. "Bloemendaal aan Zee". De 8 en Opbouw, n 15, 1935, pp. 150-160.

9 DUIKER, Jan. "Enn gezonde school voor het gezonde kind". En: De 8 en Opbouw, n ${ }^{\circ} 9$, 1932, pp. 88-92. Traducción de la autora: "Una escuela saludable para un niño sano".

${ }^{10}$ Monográfico con ejemplos europeos y americanos sobre las nuevas escuelas. De 8 en Opbouw, $n^{\circ}$ 9, 1932, pp. 82-92. Publica las imágenes y los debates, con motivo de una exposición sobre las nuevas escuelas. El hecho hace patente la importancia que llegaron a tener estos nuevos centros educativos.

11 Ver DUIKER, Jan. “Enn gezonde school voor het gezonde kind". En: De 8 en Opbouw, n 9, 1932 , p. 90 . Se muestra una foto de escolares en Chicago en 1910 dando clase en el exterior pese a las bajas temperaturas. Su comentario es: "Zooiets kan in 1932 beter!" es decir: "ien 1932 lo podemos hacer mejor!". Traducción de la autora.

12 Ibídem, pp. 91-92.

13 ZANSTRA; P. "Naar aanleiding van "La Ville Radieuse"'. De 8 en Opbouw, n' 17, 1936, pp. 199-210.

14 Para la evolución del parque popular. Ver: PANZINI, Franco. Per il piacere del popolo: L'evoluzione del giardino pubblico un Europa. Bolonia: Zanichelli Ed., 1993.

15 Denominación neerlandesa para Nueva Construcción o Neues Bauen. 


\section{El parque público o Volkspark ${ }^{14}$}

Este proceso llevó al parque urbano burgués a reinventarse. El sentido de practicidad y de economía funcional marcaría las trazas de los nuevos jardines públicos. El nuevo contexto social fue determinante: el parque de las primeras décadas del siglo XX declaraba el inicio de una fase histórica, donde el bienestar de las clases menos pudientes, pero numéricamente superiores, se convirtió en prioridad y referencia para la composición del paisaje. Se imponía una concepción más utilitarista, ligada a una cultura urbana de masas que trajo consigo unos principios higienistas, deportivos y recreativos ligados a los espacios verdes.

El espacio para estos parques, a menudo de gran tamaño, se encontró en los límites de la ciudad. El diseño de estos parques se caracterizaba por su sobriedad: trazado racional a base de líneas rectas, vastas superficies transitables, zonas de agua para bañarse en verano, patinar en invierno o practicar deportes náuticos. Los caminos pintorescos y los arriates de flores fueron sustituidos por recorridos simples y directos, y los espacios se definían mediante masas arboladas de especies autóctonas, sin concesión al exotismo, con grandes superficies herbáceas, rodeadas por masas arbóreas, de fácil mantenimiento.

El jardín público se convirtió en una especificidad tipológica, incorporado plenamente a una ciudad en la que crecían la demanda de funcionalidad, y la necesidad de enfrentarse directamente con los problemas de la vida urbana: las funciones del parque se precisaron, evolucionado desde simple equipamiento hasta una integración en la ciudad basada en una eficiencia racional, siguiendo los principios de la Niewe Bauen ${ }^{15}$.

[6]

[6] Friedrich Ebert Reform School de Ernst May. Se observa en el plano que todas las aulas y las zonas comunes tienen su equivalente al exterior para permitir la mayor parte de las actividades al aire libre. El edificio huye de planteamientos masivos y se desparrama por la ladera. Fuente: DUIKER, Jan, "Enn gezonde school voor het gezonde kind". De 8 en Opbouw, $n^{\circ} 9$, 28 de abril de 1932, p. 91.

[7] Duiker muestra una fotografia del proyecto de Ernst May, Friedrich Ebert Reform School: a cada aula le corresponde un espacio abierto donde dar clase cuando la meteorología lo permita. Las grandes puertas correderas de vidrio permiten la total interconexión entre el exterior y el interior del aula. Fuente: DUIKER, Jan, "Enn gezonde school voor het gezonde kind". De 8 en Opbouw, n० 9,28 de abril de 1932 , p. 92.

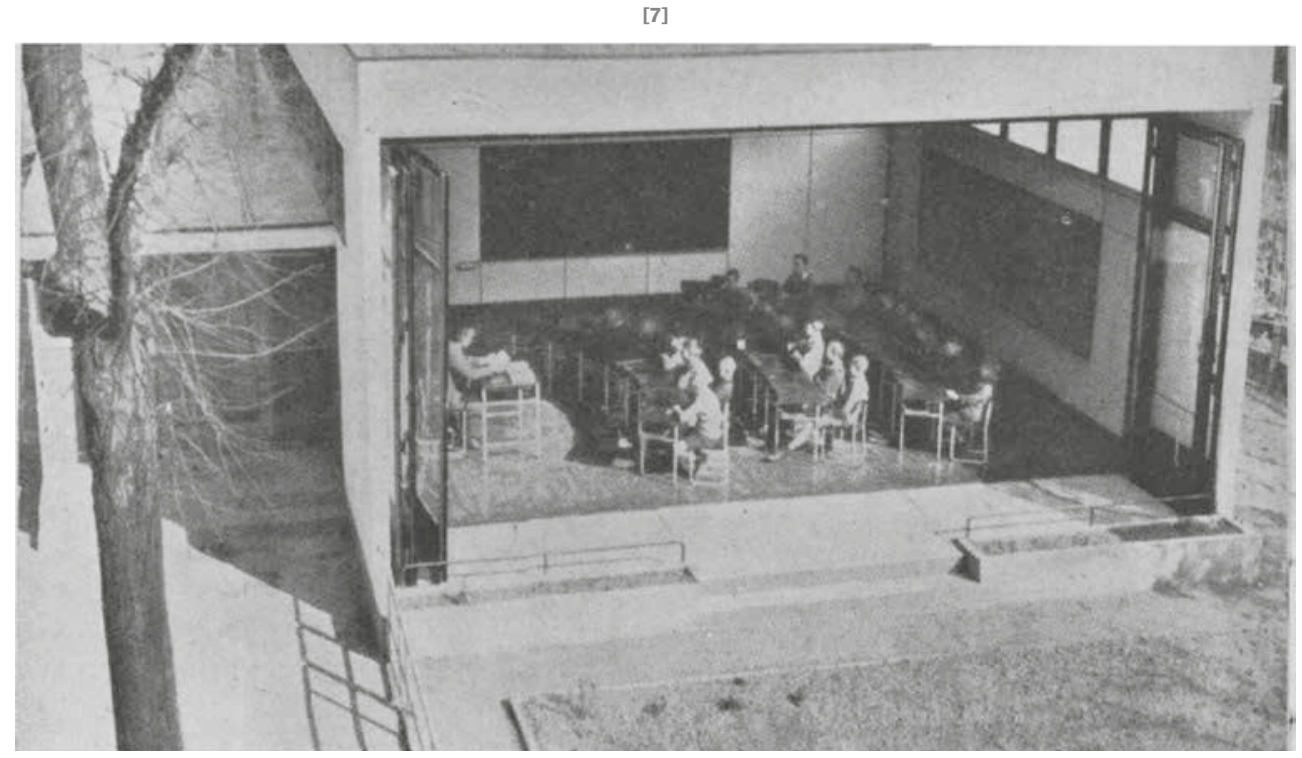

enosescross

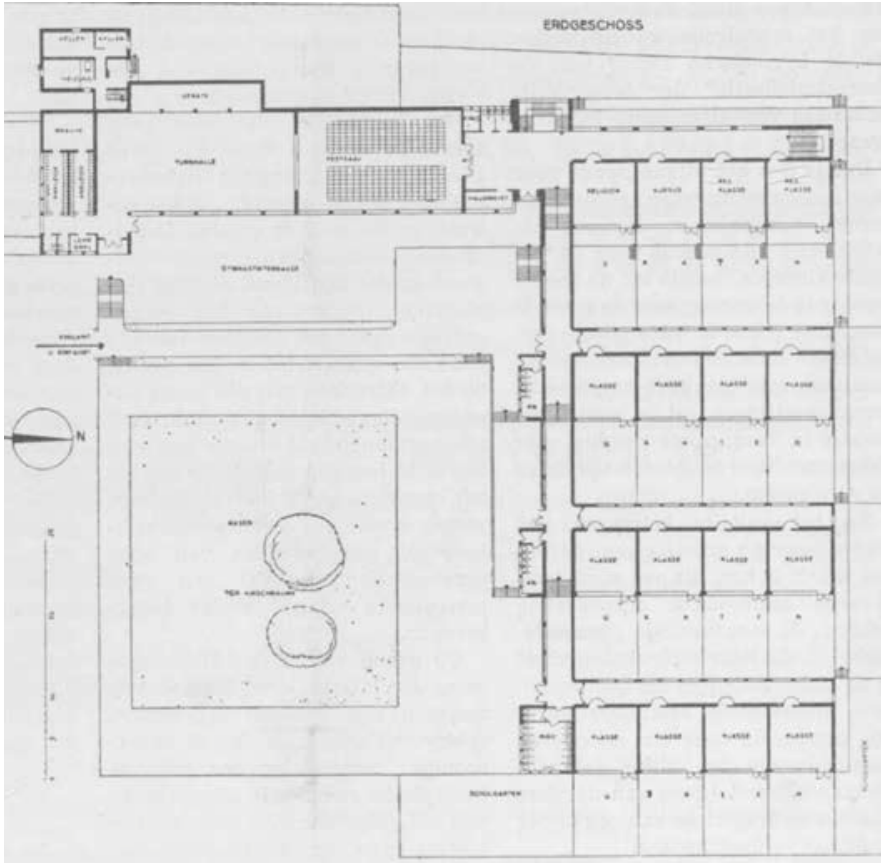

[7] 


\section{El bosque de Ámsterdam ${ }^{16}$}

Es el resultado de una serie de proyectos llevados a cabo desde los años veinte, que reflejaban la necesidad de instaurar una gran área verde en la ciudad. [9] Por fin se tomó como definitivo el proyecto del año 1934, a cargo de Cor Van Eesteren, con la colaboración de Jakoba Mulder, entonces arquitecta municipal de Ámsterdam y Jan Byhouver, paisajista, en un gran pólder de superficie aproximada de un millón de metros cuadrados. Fue la mayor intervención de este tipo hasta la fecha.

El proyecto se desarrolló en cuatro niveles diferentes: bosque, espacios abiertos, agua y comunicaciones. Las áreas libres, que se sucedían a través del bosque, alojaban las diferentes actividades deportivas y de ocio -incluso un teatro al aire libre (open lucht theater)- ${ }^{17}$. Las zonas de agua, de trazado irregular, albergaban también diferentes usos, a los que correspondían diferentes formas: "el mar nuevo" (Het Nieuwe Meer), las piscinas o el canal -este último de trazado regular, respondiendo exclusivamente a su uso deportivo-. Los dos sistemas -agua y espacios libres- se entrecruzan y se abren paso a través del bosque, confiriendo unidad al conjunto. Los recorridos, por agua o a pie, comunicaban las diferentes partes de la intervención. [10]

El parque -o bosque- fue un éxito desde el punto de vista social y urbano para la ciudad de Ámsterdam y hoy en día sigue formando parte de la vida de los ciudadanos.

\section{Lo verde como sistema}

Durante los primeros años del siglo, el modo de entender la construcción de la ciudad estaba en crisis. A raíz del esfuerzo en racionalizar el desarrollo de la metrópoli, la concepción de la función de los espacios verdes en el entorno urbano cambiaría de manera sustancial, con la adopción del proceso proyectual a gran escala. Mientras ganaba consistencia la concepción que entendía el verde como sistema capaz de interferir en la ciudad, durante los años treinta la temática dejó de lado el arte de los jardines por la planificación urbana, como evidencia la atención prestada a los proyectos de grandes parques o las nuevas actuaciones urbanas como Bosch en Lommer ${ }^{18}$ o el Plan Verde de Rotterdam.

El verde urbano como sistema es el fenómeno y el producto último del proceso que desde el siglo XIX tendía a la integración entre el campo y la ciudad y el control del territorio mediante la difusión de las técnicas de planificación (zonning) basadas en una normalización estandarizada de las relaciones cuantitativas entre los diversos componentes de la ciudad. El aumento dimensional de la intervención, que asigna siempre un peso mayor a los instrumentos generales de la planificación, y la introducción de nuevos métodos -análisis sociológico, de previsión de dimensionados, de accesibilidad y de tráfico- exigían para la configuración del proyecto una nueva concepción del parque público y del sistema de zonas verdes.

Entre las experiencias previas más interesantes en ese sentido destacan las de Bruno Taut y del paisajista Leberecht Migge, quien había colaborado con Taut y con muchos otros

[8]

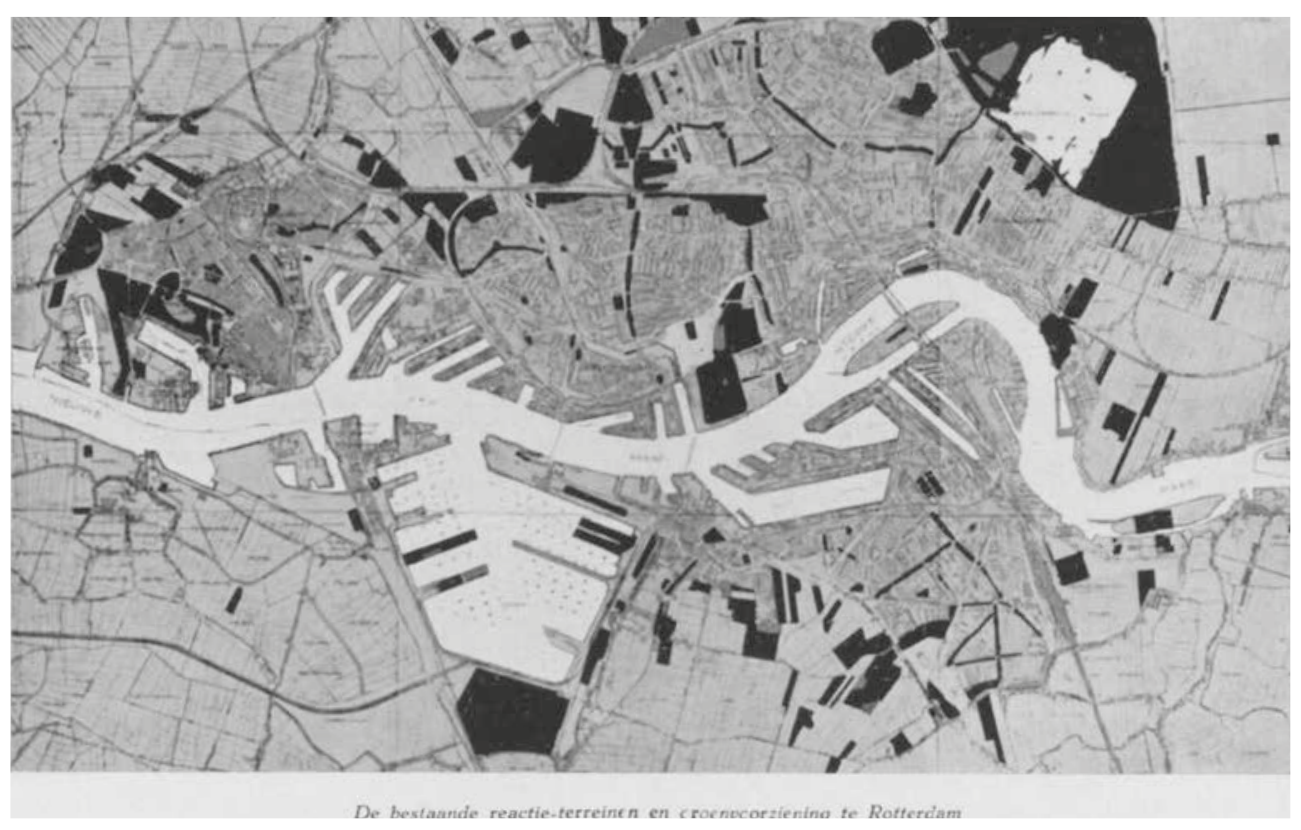

[8] Plano de estudio para el Groenplan Rotterdam, en el que se identifican los lugares en os que se debe intervenir con el objetivo de tejer el entramado de vegetación y espacios libres para una ciudad más abierta y saludable. Fuente: VAN GELDEREN. “Groenplan Rotterdam. Collectieve studie van de vereeniging "Opbouw" te Rotterdam". De 8 en Opbouw, $\mathrm{n}^{\circ} 16$, agosto de 1939 , p. 166 
16 BYHOUVER, Jan. "Het Amsterdamsche Boschpark". De 8 en Opbouw, n 2, 1937, pp. 1-10. El proyecto se presenta mediante planos y maquetas. El artículo incluye fotografias del estado actual del lugar.

${ }^{17}$ El teatro al aire libre del Amsterdam Bosch, que aparece en el monográfico "Open lucht theaters". En: VAN DER POEL, D.C. "Plan en outillage - "problemen" en eisen". De 8 en Opbouw, $n^{\circ} 4-5,1939$, pp. 46-47, en el que se muestran los nuevos teatros al aire libre, tanto alemanes como holandeses. Este monográfico consta de varios artículos, como: VAN DE VIES, Abraham. "Oude en nieuwe theaters in de open lucht", pp. 31-36, en el que relata la historia de los teatros al aire libre desde la Antigüedad.

${ }^{18}$ Bosch en Lommer fue el último gran proyecto urbano con la incorporación de zonas verdes publicado en $\mathrm{De} 8$ en Opbow. Se reservaron dos números completos para su publicación: $n^{\circ} 23$ y 24 , noviembre 1939 , pp. 249-266. El proyecto fue obra colectiva del Grupo de 8 y, aunque no se construyó, su trazado en general se respetó cuando se urbanizó después de la guerra. Para una comprensión completa del papel de Bosch en Lommer en el desarrollo de Ámsterdam, HELINGA, Helma. "Plan general de expansión de Ámsterdam". Cuaderno de Notas, $n^{\circ} 5$, 1997, pp. 13-38.

${ }^{19}$ Ver: ARREDONDO GARRIDO, David. "The influence of Leberecht Migge in the creation of the modern productive Siedlungen". VLC arquitectura, Vol. 5, Issue 2 , 2018, pp. 29-58.

20 TAUT, Bruno. "Neu-Magdeburg, eine realistische Selbstbetrachtung". [EI Nuevo Magdeburgo, una autorreflexión realística]. En: Früchlich, $\mathrm{n}^{\circ} 3,1922$, pp. 65-71.

21 MIGGE, Leberecht. "Das grüne Manifest". Die Tat, $\mathrm{n}^{\circ}$ 10, 1919, pp. 912-919.

22 META HÜLBUSCH, Inge, "Ciascuno è autosuficiente - II Verde Coloniale di Leberecht Migge". En: VV.AA. Werkbund, Germania, Austria, Svizera. Venecia: Ed. La Biennale di Venezia, 1977, pp. 66-71.

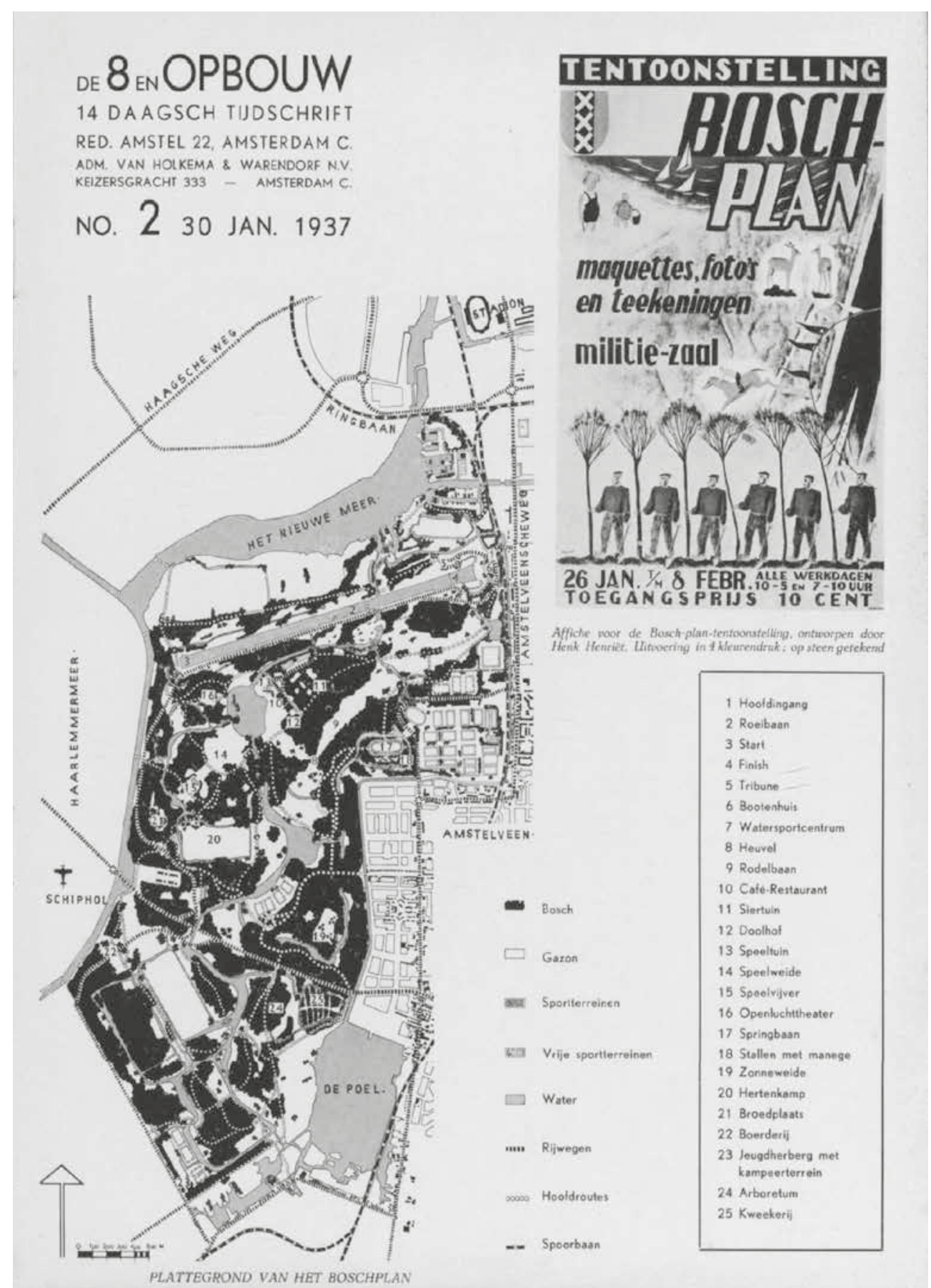

[9]

arquitectos berlineses en el desarrollo paisajístico de las Siedlungen berlinesas de los veinte ${ }^{19}$. Tanto Taut como Migge plantearon la introducción de los elementos verdes en la ciudad de manera manifiesta. Los ejemplos más claros son la propuesta para Magdeburgo ${ }^{20}$, de 1922, en la que Taut planteaba un sistema de "capas" en el que la verde permitiría una lectura globalizadora. Migge propone un plan para Frankfurt basado en otro plan anterior de 1928 denominado "Parque Municipal Colonizador". El propio nombre indica hasta qué punto la zona "vegetación" se concibe como estructurante en la concepción misma de la ciudad. No en vano Migge predicaba: "iCread la ciudad-campo, cread el campociudad!" 21. Ambas propuestas se articulaban a diferentes escalas, desde la individual de los jardines productivos o Schebergärten ${ }^{22}$ a los colectivos: jardines urbanos, parques y grandes dotaciones verdes.

Las propuestas de los arquitectos holandeses se diferenciaban de los ejemplos alemanes por su obstinación casi fundamentalista por la función en sentido moderno. Esto produjo una pérdida de interés hacia el jardín como espacio singular, para valorar como dato cualitativamente más interesante la interconexión con el contexto territorial. El jardín público se convirtió en el verde urbano y territorial: de este modo se consiguió su presencia generalizada, perdiendo su reconocimiento formal, transformándose en materia difusa e intersticial, incierta en su contenido compositivo. 


\section{Groenplan Rotterdam ${ }^{23}$}

El Plan Verde de Rotterdam fue uno de los más ambiciosos y visionarios proyectos urbanos hasta la fecha, adelantándose en diez años y una guerra al Plan general de Estocolmo. [11] Faltó tiempo para su desarrollo y ejecución, y solo conocemos las conclusiones del estudio de campo y los planteamientos iniciales de Van Gelderen.

El proyecto evidencia el cambio trascendental en la interpretación del paisaje, considerado no por su valor decorativo sino por su valor funcional -esa transformación se había ido operando ya desde la incorporación del verde como "zona"-, como reflejan estas reveladoras palabras de Van Gelderen:

"La gran necesidad que vamos observando en el último cuarto de siglo de áreas para deportes y juegos, el deseo de la vida al aire libre y recreación activa han cambiado las opiniones sobre el paisajismo. La importancia de este con intenciones decorativas perdió su valor con respecto a la concepción de las áreas de deportes, parques infantiles, populares, jardines familiares, etc." ${ }^{24}$.

El plan fue publicado como contribución del Grupo de Rotterdam (Opbouw) en la reunión de delegados del CIAM en La Sarraz en 1936 y en el Congreso de París en 1937.

El Grupo contó con el asesoramiento del paisajista Jan Bijhouwer. El estudio comenzó en 1935 y supuso tres años de trabajo de campo, estudios fotográficos, etc., centrados en la manera en que los ciudadanos vivían sus zonas libres, verdes o baldías, y la búsqueda de soluciones para configurar un sistema de zonas abiertas para una ciudad más saludable. La respuesta se trabajó a diferentes escalas: vecindario, barrio y distrito, incorporando los espacios verdes también en diferentes tamaños, dependiendo de las necesidades. Así, cada vecindario dispondría de un pequeño parque con zonas diferenciadas para las actividades, buurtpark con $400 \mathrm{~m}^{2}$, cada barrio tendría su wijkpark, de $1.000 \mathrm{~m}^{2}$, y cada distrito contaría con una gran área verde, stadtpark, de $4.000 \mathrm{~m}^{2}$, partiendo de los estándares establecidos ${ }^{25}$.

Llama la atención el interés tan evidente en justificar cada área a través de las funciones de cada una de ellas. En cada una de las áreas aparece señalada la actividad a la que esta está vinculada, y la edad de aquellos que la disfrutarán. La señalética diseñada para este fin incluye un estudio de las actividades por edades, incluyendo las actividades vinculadas a los huertos productivos. [12] [13]

La llegada de la guerra impidió el desarrollo del proyecto, que quedó limitado a lo publicado en las páginas de la revista. Muchos años más tarde, y tras la reconstrucción de la ciudad, el Ayuntamiento de Ámsterdam retomó la idea como parte de sus políticas verdes. En 2005, y bajo el mismo nombre, Groenplan Rotterdam ${ }^{26}$, se diseñó un plan para la implementación y sistematización de las zonas verdes que incluía jardines, parques -tanto urbanos como regionales-, ríos y canales, y las conexiones entre todos estos elementos. En el estudio se dibuja

[10]

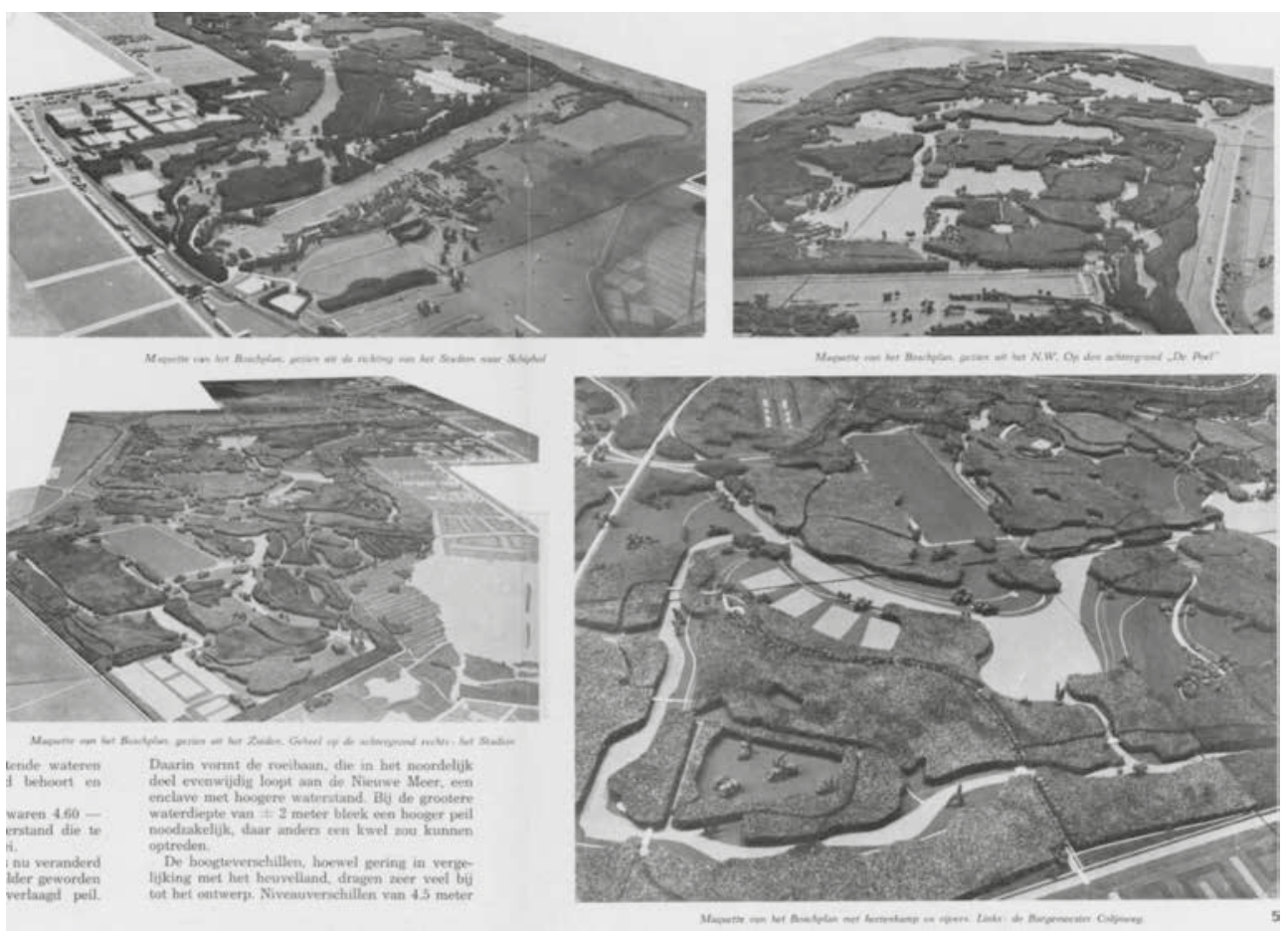

[10] Fotografias de la maqueta del Bosque de Ámsterdam, en las que se ve el denso arbolado, los caminos y las estancias horadados en el bosque asi como las zonas de agua (el mar, los rios y el canal de remo). Fuente: BYHOUVER, Jan, "Het Amsterdamsche Boschpark". De 8 en Opbouw, n 2, 30 de enero 1937, p. 1

[11] Portada de de 8 en Opbow, n ${ }^{\circ} 6$ de agosto de 1939, en el que se expone el Groenplan Rotterdam o Plan Verde para Rotterdam. Se pueden ver las fotografias que se utilizaron para el estudio previo en las que se pretendía comprender cómo los ciudadanos habitaban los espacios abiertos de la ciudad tanto verdes como baldíos. Fuente: De 8 en Opbow, n 6, 1939.

[12] Tabla de estudio de actividades al aire libre para todas las edades que se ilustra mediante una señalética diseñada para este fin y que se utiliza en los planos de parques para señalar las actividades de cada zona Fuente: VAN GELDEREN. "Groenplan Rotterdam. Collectieve studie van de vereeniging "Opbouw" te Rotterdam". De 8 en Opbouw, $n^{\circ} 16$, agosto de 1939, p. 162

[12] Propuesta de parques y dotaciones verdes para las diferentes escalas: Parque del vecindario, buurtpark, $400 \mathrm{~m}^{2}$, Parque del distrito, wijktpark: $1.000 \mathrm{~m}^{2}$ y stadpark $4.000 \mathrm{~m}^{2}$. En los planos de los dos parques se observa la utilización de la señalética de actividades por edades, donde cada área tiene su función definida. Fuente: VAN GELDEREN. "Groenplan Rotterdam. Collectieve studie van de vereeniging "Opbouw" te Rotterdam". De 8 en Opbouw, n 16, agosto de 1939, pp. 172. 


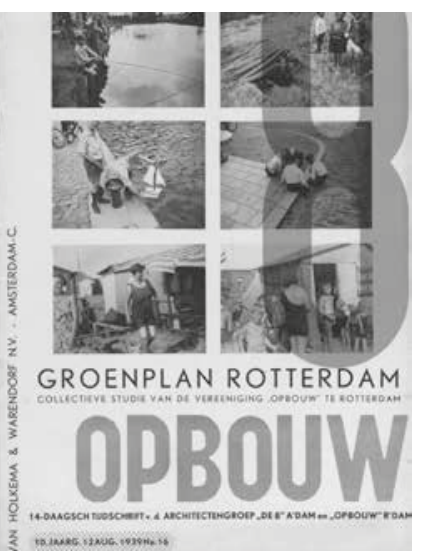

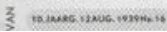

[11]

${ }^{23}$ Monográfico sobre el Plan Verde de Rotterdam. VAN GELDEREN. "Groenplan Rotterdam. Collectieve studie van de vereeniging "Opbouw" te Rotterdam". De 8 en Opbouw, $\mathrm{n}^{\circ} 16$, agosto de 1939, pp. 161-174.

$\mathbf{2 4}$ Traducción de la autora: "De sterk toegenomen behoefte in de laatste kwart eeuw aan terreinen voor sport en spel beoefening, het verlangen naar verblijf in de open lucht en actieve recreatie hebben de opvattingen over groenvoorziening sterk gewijzigd. De beteekenis van

groenvoorziening met decoratieve oogmerken verloor haar waarde t.a.v. groenvoorziening in de zin van sport, speelterreinen, volks, familietuinen, enz, enz." lbídem, p. 161

25 Ver planos en: De 8 en Opbouw, $\mathrm{n}^{\circ} \mathbf{1 6}$, 1939, pp. 170-171.

${ }^{26}$ DE GREEF, Pieter; DEN HEIJER, Marco; TILLIE, Nico. Rotterdam.

Uitvoeringsprogramma 2005. Rotterdam: Departamento de Planificación Espacial, Ayuntamiento de Rotterdam, 2005.

${ }^{27}$ Este artículo es parte de un trabajo de investigación que realicé junto al Profesor Rafael García García en el Departamento de Composición Arquitectónica de la ETSAM. EI trabajo consistió en un estudio exhaustivo de la publicación neerlandesa de entreguerras de 8 en Opbouw para rastrear a través de sus páginas las experiencias en torno a lo verde y la vida al aire libre. Mi agradecimiento al profesor García por su generosidad y su inestimable ayuda. el plano publicado en agosto del año 1939 [8] como parte de la investigación. La "agenda verde" se ha mantenido desde entonces.

\section{Conclusión}

La revista de 8 en Opbouw es referencia obligada para entender el desarrollo de la Arquitectura Moderna durante los años más duros del periodo de entreguerras. Durante sus 12 años de existencia puso de manifiesto el interés creciente por la salud y la higiene públicas, la necesidad de soluciones urbanas para el desarrollo de la vida y el disfrute al aire libre, y el interés, poco conocido, por las zonas verdes planteadas como dotación y estructura urbana, con ejemplos ineludibles, como el Bosque de Ámsterdam o el Plan Verde para Rotterdam. Este artículo recupera estas experiencias y las sitúa en su contexto, tratando de mostrar su gran valor, olvidado a causa de la llegada de la Guerra.

Aunque desconocido en gran parte, este trabajo colectivo de investigación marcó la línea de trabajo de los arquitectos más jóvenes: Bakema, Van den Broek, Van Eyck y muchos otros bebieron de las experiencias de sus mayores, que les posicionaron en una situación privilegiada para evolucionar hacia la revisión de la Arquitectura Moderna tras el conflicto bélico ${ }^{27}$.

[12]

\begin{tabular}{|c|c|c|c|c|c|c|c|c|c|c|}
\hline $0-2$ & $\because \frac{\pi}{2}$ & $\pi \times$ & 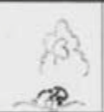 & & & & & & & \\
\hline 8-6 & दो & $x$ & $\Leftrightarrow$ & & & & & & & \\
\hline $7-14$ & ك & $\$$ & 8 & 贫 & 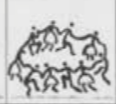 & $x=$ & of & ad & & \\
\hline I5-24 & & insisin & S. & & & xi & & & & \\
\hline & of & . & $\Rightarrow \Rightarrow A$ & - & & $\Rightarrow$ & 2 & & 5 & \\
\hline $25-50$ & $\therefore$. & \$) & $\dot{\phi} \dot{\lambda}$ & $\hat{S}^{\circ}$ & 㫕 & C & - & + & 3 & 5 \\
\hline $50+$ & on & त' & & & & & & & & \\
\hline
\end{tabular}

[13]

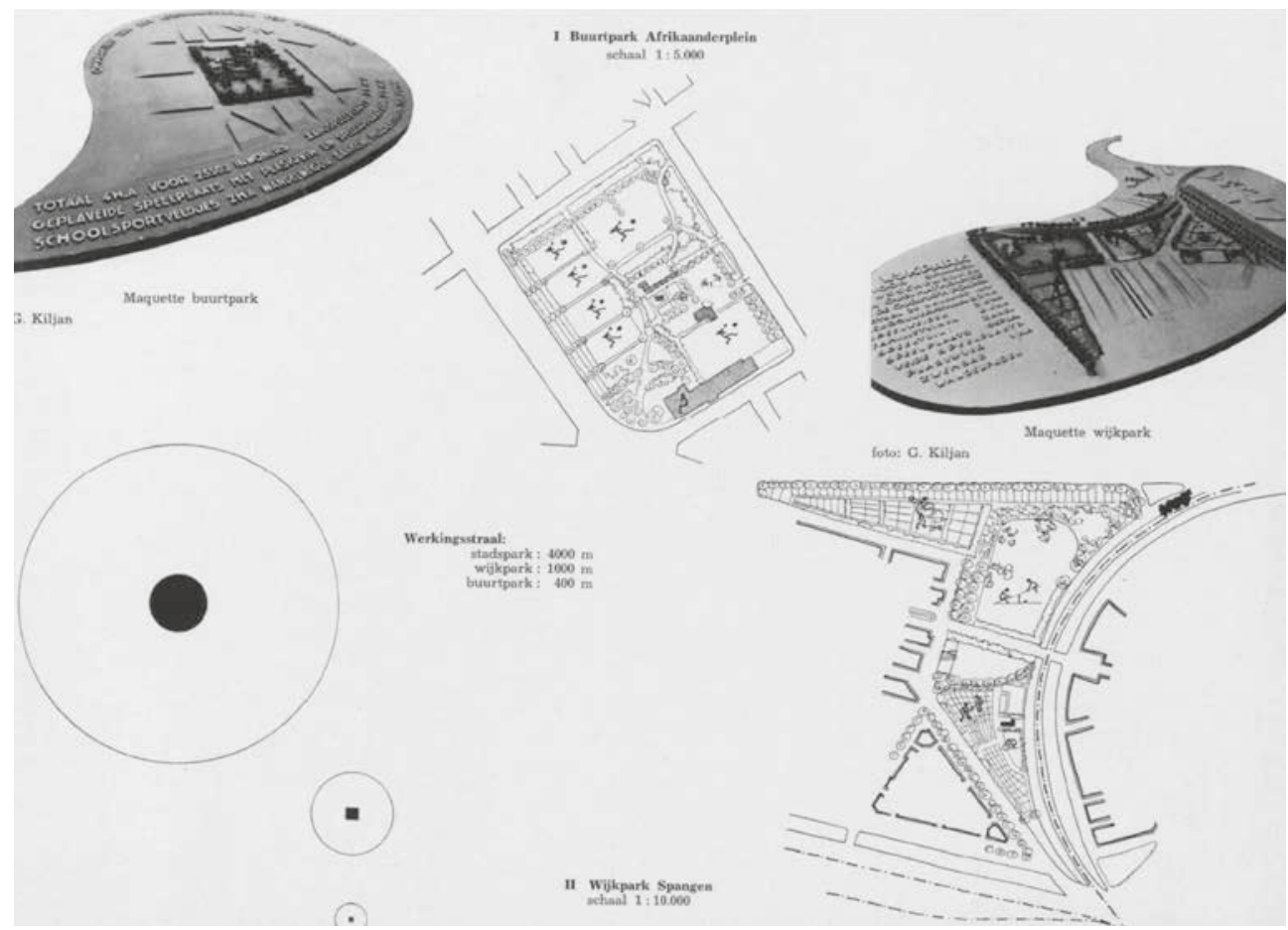




\title{
03 | Lo verde como sistema: espacios verdes y vida al aire libre en la Holanda de entreguerras a través de las páginas de la publicación neerlandesa de 8 en Opbouw _Isabel de Cárdenas Maestre
}

\begin{abstract}
La revista holandesa de 8 en Opbouw, heredera de 110 fue, desde su creación en 1932 hasta su desaparición por causas políticas en 1943, uno de los últimos reductos de la Neues Bauen. Integrada por los grupos holandeses de 8 y OPBOUW, se mantuvo siempre atenta a las experiencias que se estaban desarrollando en otros paises, especialmente la Francia de Le Corbusier, Alemania, la Unión Soviética o Estados Unidos. Por esta razón, acogieron con grandísimo interés las nuevas teorías de reforma de la vida y la necesidad de revisar los modelos de la ciudad decimonónica, entre otros muchos temas. Este trabajo se centra precisamente en la búsqueda de artículos referidos a los espacios verdes o a la necesidad de vida al aire libre descubriendo, no solo la urgencia con que demandaron politicas de higiene y zonas verdes, sino, sobre todo a partir de 1938 , muchos proyectos de un altísimo interés paisajístico y urbano, que bebian de propuestas alemanas de los años 20 y de la Nueva Objetividad. Mención ineludible merecen los proyectos del Ámsterdam Bosch, el Plan Verde para Rotterdam o decenas de proyectos de dotaciones para baños públicos, piscinas o escuelas que se presentan.
\end{abstract}

\section{Palabras clave}

Neues Bauen, Lebensreform, paisaje, parque, de 8 en Opbouw, Rotterdam Grenplan, higiene, urbanismo

\section{3 | Lo verde como sistema: espacios verdes y vida al aire libre en la Holanda de entreguerras a través de las páginas de la publicación neerlandesa de 8 en Opbouw_Isabel de Cárdenas Maestre}

ARREDONDO GARRIDO, David. "The influence of Leberecht Migge in the creation of the modern productive Siedlungen". VLC arquitectura, Vol. 5, Issue 2, 2018.

BOCK, Manfred. "Ensayo sobre de 8 en Opbouw". Prologado por GARCÍA GARCÍA, Rafael, en Cuaderno de Notas, ${ }^{\circ} 8,2000$.

BROWN, Jeremy. Influenza: The Hundred-Year Hunt to Cure the 1918 Spanish Flu Pandemic. Nueva York: Atria Paperback, 2018

BYHOUVER, Jan. "Het Amsterdamsche Boschpark". De 8 en Opbouw, n 2, 1937.

DUIKER, Jan. "Enn gezonde school voor het gezonde kind". ["Una escuela saludable para un niño sano"]. De 8 en Opbouw, n 9, 1932.

FALKENBERG, Ida. "Her Naturbad". [Baños naturales]. De 8 en Opbouw, n 17, 1933.

META HÜLBUSCH, Inge. "Ciascuno è autosuficiente - II Verde Coloniale di Leberecht Migge". En: AA.VV. Werkbund. Germania, Austria, Svizera. Venecia: Ed. La Biennale di Venezia, 1977.

MIGGE, Leberecht. "Das grüne Manifest". Die Tat, n 10, 1919.

Monográficos sobre la escuela y la infancia. De 8 en Opbouw, $n^{\circ} 9$ y n 14,$1932 ; n^{\circ} 4,1933 ; n^{\circ} 3$ y $n^{\circ} 22,1935 ; n^{\circ} 15,1939$.

Monográficos sobre la higiene y el deporte. De 8 en Opbouw, $n^{\circ} 16,1932 ; n^{\circ} 10$ y $n^{\circ} 17,1933 ; n^{\circ} 15$ y $n^{\circ} 18,1935 ; n^{\circ} 16,1936 ; n^{\circ} 7,1938 ; n^{\circ} 2,1940$.

Monográficos sobre parques y zonas verdes. De 8 en Opbouw, $n^{\circ} 3,1937 ; n^{\circ} 15, n^{\circ} 16, n^{\circ} 20, n^{\circ} 21$ y n 22,$1939 ; n^{\circ} 2$ y $n^{\circ} 3,1942$.

PANZINI, Franco. Per il piacere del popolo: L'evoluzione del giardino pubblico un Europa. Bolonia: Zanichelli Ed., 1993.

STAAL, Arthur. "Bloemendaal aan Zee". De 8 en Opbouw, n 15, 1935.

TAUT, Bruno. "Neu-Magdeburg, eine realistische Selbstbetrachtung". Früchlich, n $3,1922$.

VAN DE VIES, Abraham. "Oude en nieuwe theaters in de open lucht". De 8 en Opbouw, n' 4-5, 1939.

VAN DER POEL, D.C. "Plan en outillage - "problemen" en eisen". De 8 en Opbouw, n 4-5, 1939.

VAN GELDEREN. "Groenplan Rotterdam. Collectieve studie van de vereeniging "Opbouw" te Rotterdam". De 8 en Opbouw, n $16,1939$.

ZANSTRA; P. "Naar aanleiding van "La Ville Radieuse"”. De 8 en Opbouw, n, 1936. 